\title{
THE HARMONIC INDEX OF TWO-TREES AND QUASI-TREE GRAPHS
}

\author{
XiaOling Sun, Yubin GaO AND Jianwei Du
}

\begin{abstract}
The harmonic index of a graph $G$ is defined as the sum of the weights $\frac{2}{d(u)+d(v)}$ of all edges $u v$ of $G$, where $d(u)$ denotes the degree of the vertex $u$ in $G$. A graph $G$ is called quasi-tree, if there exists $u \in V(G)$ such that $G-u$ is a tree. The graphs called two-trees are defined by recursion. The smallest two-tree is the complete graph on two vertices. A two-tree on $n+1$ vertices (where $n \geqslant 2$ ) is obtained by adding a new vertex adjacent to the two end vertices of one edge in a two-tree on $n$ vertices. In this work, the sharp lower and upper bounds on the harmonic index of quasi-tree graphs are presented. Furthermore, the lower bound on the harmonic index of two-trees is presented, and the two-trees with the minimum and the second minimum harmonic index, respectively, are determined.
\end{abstract}

Mathematics subject classification (2010): 05C07, 05C15.

Keywords and phrases: Harmonic index, two-tree, quasi-tree graph, cycle.

\section{REFERENCES}

[1] L. ZHONG, The harmonic index for graphs, Appl. Math. Lett., 25, (2012), 561-566.

[2] S. FajtlowicZ, On conjectures of Graffiti-II, Congr. Numer., 60, (1987), 187-197.

[3] R. Wu, Z. TANG AND H. DENG, A lower bound for the harmonic index of a graph with minimum degree at least two, Filomat, 27, (2013), 51-55.

[4] L. ZHONG, The harmonic index on unicyclic graphs, Ars Combin., 104, (2012), 261-269.

[5] L. ZHONG AND K. XU, The harmonic index for bicyclic graphs, Utilitas Math., 90, (2013), 23-32.

[6] S. Wang, B. Zhou And N. Trinajstić, On the sum-connectivity index, Filomat, 25, 3 (2011), $29-42$.

[7] X. XU, Relationships between harmonic index and other topological indices, Applied Mathematical Sciences, 6, (2012), 2013-2018.

[8] A. Llić, Note on the harmonic index of a graph, Arxiv: 1204.3313v1 [math.CO], (2012).

[9] C. Delorme, O. Favaron and D. Rautenbach, On the Randic index, Discrete Math., 257, (2002), 29-38.

[10] H. Deng, Z. TAng And J. Zhang, On a conjecture of Randić index and graph radius, Filomat, 29, (2011), 1369-1375.

[11] J. GaO And M. Lu, On the Randić index of unicyclic graphs, MATCH Commun. Math. Comput. Chem., 53, (2005), 377-384.

[12] S. LiU AND J. LI, Some properties on the harmonic index of molecular trees, ISRN Applied Mathematics, 2014, (2014), 1-17.

[13] R. Wu, Z. TANG AND H. Deng, On the harmonic index and the girth of a graph, Utilitas Math., 91, (2013), 65-69.

[14] R. Todeschini And V. Consonni, Handbook of Molecular Descriptors, Wiley-VCH, Weinheim, 2000.

[15] J. A. Bondy ANd U. S. R. Murty, Graph theory with applications, Elsevier, New York, 1976.

[16] L. ZHONG AND Q. CUI, The harmonic index for unicyclic graphs with given girth, Filomat, 29, 4 (2015), 673-686.

[17] J. Li, J. LV And Y. LiU, The harmonic index of some graphs, Bull. Malays. Math. Sci. Soc., 39, (2016), 331-340. 
[18] H. Deng, S. Balachandran, S. K. Ayyaswamy And Y. B. Venkatakrishnan, The harmonic indices of polyomino chains, Natl. Acad. Sci. Lett., 37, 5 (2014), 451-455.

[19] L. ZHONG, Note on a relation between the harmonic index and the average distances of trees, Utilitas Math., 96, (2015), 277-283.

[20] L. ZHONG, The harmonic index for unicyclic and bicyclic graphs with given matching number, Miskolc Math. Notes, 16, 1 (2015), 587-605.

[21] Y. ZHU AND R. CHANG, Maximum harmonic indices of trees and unicyclic graphs with given number of pendant vertices and diameter, Utilitas Math., 93, (2014), 365-374.

[22] Z. Zhang, B. Wu AND Y. Lin, Counting spanning trees in a small-world Farey graph, Phys. A, 391, (2012), 3342-3349.

[23] Z. Zhang, H. LiU, B. Wu And T. Zhou, Spanning trees in a fractal scale-free lattice, Phys. Rev. E, 83, (2011), 129-148.

[24] Z. ZhANG, H. LiU, B. WU AND S. ZHOU, Enumeration of spanning trees in a pseudofractal scalefree web, Eur. Phys. Lett., 90, (2010), 1632-1652.

[25] Z. ZHANG, L. RONG AND C. GUo, A deterministic small-world network created by edge iterations, Phys. A, 363, (2006), 567-572. 